\title{
Sexual Violence as a Predictor of Unwanted Pregnancy: Evidence from the 2013 Nigeria Demographic and Health Survey
}

\author{
Titilayo A., \\ Obafemi Awolowo University, Ile-Ife, Nigeria. \\ Training and Research Unit, \\ North West University, Mmabatho, South Africa \\ Ekundayo O.O., \\ Olaoye-Oyesola O.J. \\ Obafemi Awolowo University, Ile-Ife, Nigeria \\ Anuodo, A.O. \\ Population Training and Research Unit, \\ North West University, Mmabatho, South Africa
}

doi: 10.19044/esj.2017.v13n20p140 URL:http://dx.doi.org/10.19044/esj.2017.v13n20p140

\begin{abstract}
Gender-based domestic violence (GBDV) continues to pose a serious threat to woman folk and the society at large. All efforts to reduce the menace have not yielded an impressive result and thus, the prevalence rate is still unacceptably high. Employing analytic nationally representative weighted sample size, 15,941women aged 15-49 years who were currently pregnant or ever had at least one pregnancy experience were interviewed for domestic violence through quantitative instrument (questionnaire). The data were analysed with a chi-squared test and binary logistic regression using STATA 13. Overall, one quarter (24.7\%) of the total respondents who ever experienced domestic violence from their spouses or intimate sexual partners reported having experienced unwanted/unintended pregnancy. It was evident in the study that GBDV is significantly related to unwanted pregnancy even after controlling for all other tested independent variables like age, educational attainment, wealth index, religion, place of residence and other fertility related variables such as number of children ever born, contraceptive use and pregnancy termination experience. Spousal abuse in any form is a crucial predictor of unwanted pregnancy in Nigeria. Therefore, addressing gender-based domestic violence is critical to reducing the menace of unwanted pregnancy and taming unnecessary population growth in Nigeria.
\end{abstract}


Keywords: Domestic, Violence, Partners, Unwanted Pregnancy, Nigeria

\section{Introduction}

Incidence of gender-based domestic violence (GBDV) in almost all countries of the world (developing and developed alike) is no longer a breaking news. GBDV, which is described as the household violence involving men and women has been with humankind in most societies of the world from time immemorial (Titilayo \& Palamuleni, 2015) even though it never gained global research attention until some two decades ago (Hammoury, Khawaja, Mahfoud, Afifi \& Madi, 2009). GBDV is so widespread and common in almost all parts of the world that it has almost become a household name, you see it in almost every neighbourhood and you hear of it in the medias every now and then (Okemini \& Adekola, 2012). Though, both sexes are susceptible to GBDV but women folk are more susceptible than their male counterparts (see Hossain, Bose \& Ahmad, 2004; Zafar, Batool \& Bano, 2005). In actual fact, gender-based domestic violence is defined as violence directed at an individual based on his or her biological sex, gender identity, or perceived adherence to socially defined norms of masculinity and femininity (USAID, 2012), but the World Health Organization (WHO) has observed domestic violence as sexually, psychologically and physically coercive acts used against adult and adolescent women by current or former male intimate partners (WHO, 1996 in Stephenson, Jadhav \& Hindin, 2013). Mostly, empirical evidence has shown that greater parts of GBDV are against women from their former or present husbands or partners (Dobash \& Dobash, 1980; Jewkes, 2002; Dodd et al., 2004; Walby \& Allen, 2004; Lamners, Ritchie \& Robertson, 2005; Hindin, Kishor \& Ansara, 2008).

Apart from other adverse effects on health and general wellbeing of the victims, studies have severally shown a link between GBDV and poor reproductive health outcomes (see Wathen \& MacMillan, 2003; Kishor \& Johnson, 2004; Himanshu \& Panda, 2007; De wet, 2009; Antai, 2011; Okemiri \& Adekola, 2012; Bibi, Ashfaq, Shaikh \& Qureshi, 2014; Solanke, 2014; Wekwete, Sanhokwe, Murenjekwa, Takavarasha \& Madzingura, 2014; Titilayo \& Palamuleni, 2015). And some other studies have evaluated the relationship between GBDV and occurrences of deaths among little children (Asling-Monemi, Naved \& Persson, 2008; Titilayo, Anuodo \& Palamuleni, 2016). But it is amazing that despite the shockingly high rate of domestic sexual violence against women from their spouses or intimate male partner worldover (Heise, Ellsberg \& Gottemoeller, 1999; WHO, 2002) and in Nigerian rural and urban societies in particular (NPC \& UNPF, 2008; NPopC \& ICF International, 2014) there is no such study that evaluate the 
relationship between gender-based domestic violence and unwanted/unintended pregnancy in Nigeria. This paper therefore explores the likely relationship between gender-based sexual violence and unwanted/unintended pregnancy in Nigeria.

\section{Materials and Method}

Data for this study were obtained from 2013 Nigeria Demographic and Health Survey (NDHS). A representative sample of 38,948 households was selected for the 2013 NDHS survey. The survey involved the use of a three-stage sampling technique and the selection procedures run thus: The sample for the 2013 NDHS was a stratified sample, selected independently in three stages from the sampling frame. Stratification was achieved by separating each state into urban and rural areas. In the first stage, 893 localities were selected with probability proportional to size and with independent selection in each sampling stratum. In the second stage, one EA was randomly selected from most of the selected localities with an equal probability selection. In a few larger localities, more than one EA was selected. In total, 904 EAs were selected. After the selection of the EAs and before the main survey, a household listing operation was carried out in all of the selected EAs. The household listing involved visiting each of the 904 selected EAs, drawing a location map, and a detailed sketch map. The research team also recorded on the household listing forms all occupied residential households found in the EA with the address and the name of the head of the household. If a selected EA included less than 80 households, a neighbouring EA from the selected locality was added to the cluster and listed completely. The resulting list of households served as the sampling frame for the selection of households in the third stage.

In the third stage of selection, a fixed number of 45 households were selected in every urban and rural cluster through equal probability systematic sampling based on the newly updated household listing (NPopC \& ICF International, 2014). The survey procedures and instruments were ethically approved by the Ethics Committee of the ICF Macro International, Inc., Calverton, Maryland, USA and the National Research Ethics Committee in Nigeria before the commencement of the data collection. Informed consent, both verbal and written was also obtained from all the individual respondents involved in the data.

The focused, target population for this study were all women in Nigeria who were selected and interviewed for domestic violence module (v044) in 2013 NDHS, while categories of women that were not selected, selected but privacy not possible and those that were selected but not interviewed were appropriately dropped from the study. Further extraction was done based on condition of present or former pregnancy which was 
captured in three categories; namely, pregnancy wanted as at then, was categorized as intended pregnancy (coded 0) while those wanted later and no more were considered as having unintended pregnancy (coded 1) which was done for each of the pregnancy experience (m10_1 to m10_6) in the last 5 years preceding the survey. Overall, respondent was known to have unintended pregnancy if she reported having pregnancy that was unintentional (wanted later or no more) in at least a case of all the pregnancy experiences in the last five years preceding the survey. Experience of domestic violence which could be physical, sexual and psychological was measured in the data by various questions, women were asked whether their present husbands ever or in the last twelve months prior to the survey date pushed, slapped, twisted arm, punched with fist, kicked or dragged, tried to choke or burn, threatened or attacked with knife and physically forced to have sexual intercourse. Any woman who answered in affirmative to at least one of the questions was referred to as having experienced domestic violence. The data were further weighted in order to remove any error of sampling randomization and representativeness biases.

To obtain information about respondents' socio-economic and demographic background the following selected variables were extracted from the dataset - age, education, wealth status, work status, religion and place of residence. Other variables extracted were pregnancy termination experience, children ever born (CEB), husband/partner work and educational status, partner alcohol in-take and contraceptive use. The weighted sample size was 15,941 women. The frequency of all variables of interest was analysed in the "total column" of Table 1 and 2. The first two tables also showed the bivariate analysis of sexual violence and unintended pregnancy with respondents' socio-demographic background and other variables respectively; which were determined using row percentage distribution and pearson's chi-square $\left(\chi^{2}\right)$ test. Two binary logistic regression models were used to test for the chance of unintended pregnancy. First model predicted unintended pregnancy (dependent/outcome variable) through sexual violence experience (main independent variable) and this was the unadjusted model. Adjusted model examined the joint-effect of sexual violence experience, respondents' socio-demographic and other factors on unintended pregnancy (model 2). All the extraction of target population from the data set, variables of interest and analyses were done using STATA 13.

\section{Ethical approval}

The Institutional Review Board of ICF International, Inc. reviewed and approved the data used for this analysis. The Institutional Review Board of ICF International complied with the United States Department of Health 
and Human Services regulations for the protection of human research subjects. The ethical approval and clearance was equally obtained by MEASURE DHS from National Ethics Committee of the country before the commencement of data collection. Informed consent both verbal and written was also obtained from all the individual respondents before the commencement of the interview. Respondents have the right and opportunity to opt out of the interview at any point. No trace of identification of the respondents was left in the process of the data collection.

\section{Results:}

Table 1: Socio-demographic Background and Sexual violence experience

\begin{tabular}{|c|c|c|c|c|}
\hline \multirow[t]{2}{*}{ Variable/Categories } & \multicolumn{2}{|c|}{ Sexual Violence } & \multirow[t]{2}{*}{ Total (\%) } & \multirow{2}{*}{$\begin{array}{l}\mathrm{p} \text {-value } \\
x^{2} \text { test }\end{array}$} \\
\hline & No & Yes & & \\
\hline Age & & & & 0.52 \\
\hline $15-24$ & 95.4 & 4.6 & 4,296 (27.0) & \\
\hline $25-34$ & 95.0 & 5.0 & $10,031(62.9)$ & \\
\hline 35 or more & 95.6 & 4.4 & $1,614(10.1)$ & \\
\hline Educational level & & & & 0.76 \\
\hline No/Low Education & 95.2 & 4.8 & 10,168 (63.8) & \\
\hline High Education & 95.1 & 4.9 & $5,773(36.2)$ & \\
\hline Wealth Index & & & & $<0.001$ \\
\hline Poor & 94.6 & 5.4 & $6,853(43.0)$ & \\
\hline Middle & 94.8 & 5.1 & 5,977 (37.5) & \\
\hline Rich & 97.1 & 2.9 & $3,110(19.5)$ & \\
\hline Work Status & & & & 0.06 \\
\hline Not working & 95.8 & 4.2 & 4,729 (29.7) & \\
\hline Working & 94.9 & 5.1 & $11,212(70.3)$ & \\
\hline Religion & & & & $<0.001$ \\
\hline Christianity & 93.1 & 6.9 & $6,448(40.6)$ & \\
\hline Islam & 96.5 & 3.5 & $9,245(58.4)$ & \\
\hline Traditional/Others & 95.0 & 5.0 & $152(1.00)$ & \\
\hline Place of Residence & & & & $<0.001$ \\
\hline Urban & 96.2 & 3.8 & 5,989 (37.6) & \\
\hline Rural & 94.5 & 5.4 & $9,952(62.4)$ & \\
\hline Pregnancy termination & & & & $<0.001$ \\
\hline No & 95.6 & 4.4 & $14,060(88.3)$ & \\
\hline Yes & 91.7 & 8.2 & $1,867(11.7)$ & \\
\hline Children Ever Born & & & & 0.12 \\
\hline $1-2$ & 95.7 & 4.3 & 5,789 (36.3) & \\
\hline $3-4$ & 95.0 & 5.0 & 4,736 (29.7) & \\
\hline 5 or more & 94.7 & 5.3 & $5,417(34.0)$ & \\
\hline Partner's work status & & & & 0.38 \\
\hline Not working & 96.6 & 3.4 & $139(0.90)$ & \\
\hline Working & 95.1 & 4.9 & $15,571(99.1)$ & \\
\hline Partner's Educational level & & & & 0.10 \\
\hline Low Education & 95.5 & 4.5 & $8,538(55.0)$ & \\
\hline High Education & 94.7 & 5.3 & $6,989(45.0)$ & \\
\hline Partner's Alcohol in-take & & & & $<0.001$ \\
\hline
\end{tabular}




\begin{tabular}{|c|r|r|r|r|}
\hline No & 96.2 & 3.8 & $12,808(82.0)$ & \\
Yes & 90.2 & 9.8 & $2,821(18.0)$ & \\
\hline Contraceptive use & & & & 0.72 \\
No & 95.1 & 4.9 & $13,196(82.8)$ & \\
Yes & 95.3 & 4.7 & $2,746(17.2)$ & \\
\hline
\end{tabular}

\section{Socio-economic and demographic background and sexual violence}

The socio-economic and demographic variables of respondents in diverse manners were seen as contributing factors to sexual violence in Nigeria. Among all, wealth, religion, place of residence, pregnancy termination and partner's alcohol intake were significantly contributing to women experience of sexual violence in Nigeria. Christian, poor women, who reside in rural areas, who had experienced pregnancy termination and whose partners take alcohol were significantly susceptible to sexual violence than their other counterparts in the study location. Apart from all these statistically significant variables, there were higher occurrences of sexual violence among women with the following characteristics - belong to age group 25-34 years, having high education, if woman is working and women had given birth to more than 4 children. Other factors were women whose partners were working and if woman was not using contraceptive (Table 1).

Table 2: Socio-demographic Background and Unintended Pregnancy

\begin{tabular}{|c|c|c|c|c|}
\hline \multirow[t]{2}{*}{ Variable/Categories } & \multicolumn{2}{|c|}{ Unintended Pregnancy } & \multirow[t]{2}{*}{ Total (\%) } & \multirow{2}{*}{$\begin{array}{l}\mathrm{p} \text {-value } \\
x^{2} \text { test }\end{array}$} \\
\hline & No & Yes & & \\
\hline Age & & & & $<0.05$ \\
\hline $15-24$ & 87.9 & 12.1 & $4,296(27.0)$ & \\
\hline $25-34$ & 90.1 & 9.9 & $10,031(62.9)$ & \\
\hline 35 or more & 89.1 & 10.9 & $1,614(10.1)$ & \\
\hline Educational level & & & & $<0.001$ \\
\hline Low Education & 92.9 & 7.1 & 10,168 (63.8) & \\
\hline High Education & 83.3 & 16.7 & $5,773(36.2)$ & \\
\hline Wealth Index & & & & $<0.001$ \\
\hline Poor & 94.1 & 5.9 & $6,853(43.0)$ & \\
\hline Middle & 85.6 & 14.4 & 5,977 (37.5) & \\
\hline Rich & 86.3 & 13.7 & $3,110(19.5)$ & \\
\hline Work Status & & & & $<0.05$ \\
\hline Not working & 90.8 & 9.2 & 4,729 (29.7) & \\
\hline Working & 88.8 & 11.2 & $11,212(70.3)$ & \\
\hline Religion & & & & $<0.001$ \\
\hline Christianity & 80.9 & 19.1 & $6,448(40.6)$ & \\
\hline Islam & 95.2 & 4.8 & 9,245 (58.4) & \\
\hline Traditional/Others & 95.9 & 4.1 & $152(1.00)$ & \\
\hline Place of Residence & & & & $<0.001$ \\
\hline Urban & 86.8 & 13.2 & 5,989 (37.6) & \\
\hline Rural & 91.0 & 9.0 & $9,952(62.4)$ & \\
\hline $\begin{array}{l}\text { Pregnancy termination } \\
\text { No }\end{array}$ & 90.0 & 10.0 & 14,060 (88.3) & $<0.001$ \\
\hline
\end{tabular}




\begin{tabular}{|c|c|c|c|c|}
\hline Yes & 84.8 & 15.2 & $1,867(11.7)$ & \\
\hline Children Ever Born & & & & $<0.05$ \\
$1-2$ & 88.9 & 11.1 & $5,789(36.3)$ & \\
$3-4$ & 90.7 & 9.3 & $4,736(29.7)$ & \\
5 or more & 88.8 & 11.2 & $5,417(34.0)$ & \\
\hline Partner's work status & & & & 0.65 \\
Not working & 89.4 & 10.6 & $139(0.9)$ & \\
Working & 90.5 & 9.5 & $15,571(99.1)$ & \\
\hline Partner’s Educational level & & & & $<0.001$ \\
Low Education & 93.1 & 6.8 & $8,538(55.0)$ & \\
High Education & 87.2 & 12.8 & $6,989(45.0)$ & \\
\hline Partner’s Alcohol in-take & & & & $<0.001$ \\
No & 92.6 & 7.4 & $12,808(82.0)$ & \\
Yes & 80.9 & 19.1 & $2,821(18.0)$ & \\
\hline Contraceptive use & & & & $<0.001$ \\
No & 91.6 & 8.4 & $13,196(82.8)$ & \\
Yes & 78.8 & 21.2 & $2,746(17.2)$ & $<0.001$ \\
No & & & & \\
Yes & 91.3 & 8.7 & $14,876(95.1)$ & \\
\hline
\end{tabular}

\section{Socio-demographic background and unintended pregnancy}

Table 2 considered the bivariate relationship between the selected socio-economic and demographic variables and experience of unwanted pregnancy. Statistical analysis revealed that of all the variables only partner's work status was not statistically significant in relation to experience of unwanted pregnancy. Other variables ranging from age of respondents to the experience of sexual violence revealed a significant relationship with experience of unwanted pregnancy though in diverse rates.

Table 3

\begin{tabular}{|c|c|c|c|c|}
\hline \multirow{2}{*}{ Variables/Categories } & \multicolumn{2}{|c|}{ Model 1 } & \multicolumn{2}{c|}{ Model 2 } \\
\cline { 2 - 5 } & Odds & (95 CI) & Odds & (95 CI) \\
\hline Sexual violence & & & & \\
No & RC & & RC & \\
Yes & $2.92^{* *}$ & $(2.47-3.44)$ & $2.73^{* *}$ & $(2.28-3.27)$ \\
\hline Age & & & & \\
$15-24$ & & & RC & \\
$25-34$ & & & $0.46^{* *}$ & $(0.39-0.54)$ \\
35 or more & & & $0.43^{* *}$ & $(0.34-0.55)$ \\
\hline Educational level & & & \\
Low Education & & & RC & \\
High Education & & & $1.35^{* *}$ & $(1.17-1.57)$ \\
\hline Wealth Index & & & \\
Poor & & & $1.51^{* *}$ & $(1.29-1.75)$ \\
Middle & & & $1.29^{*}$ & $(1.04-1.61)$ \\
Rich & & & & \\
\hline Work Status & & & RC & \\
\hline Not working & & & & \\
\hline
\end{tabular}




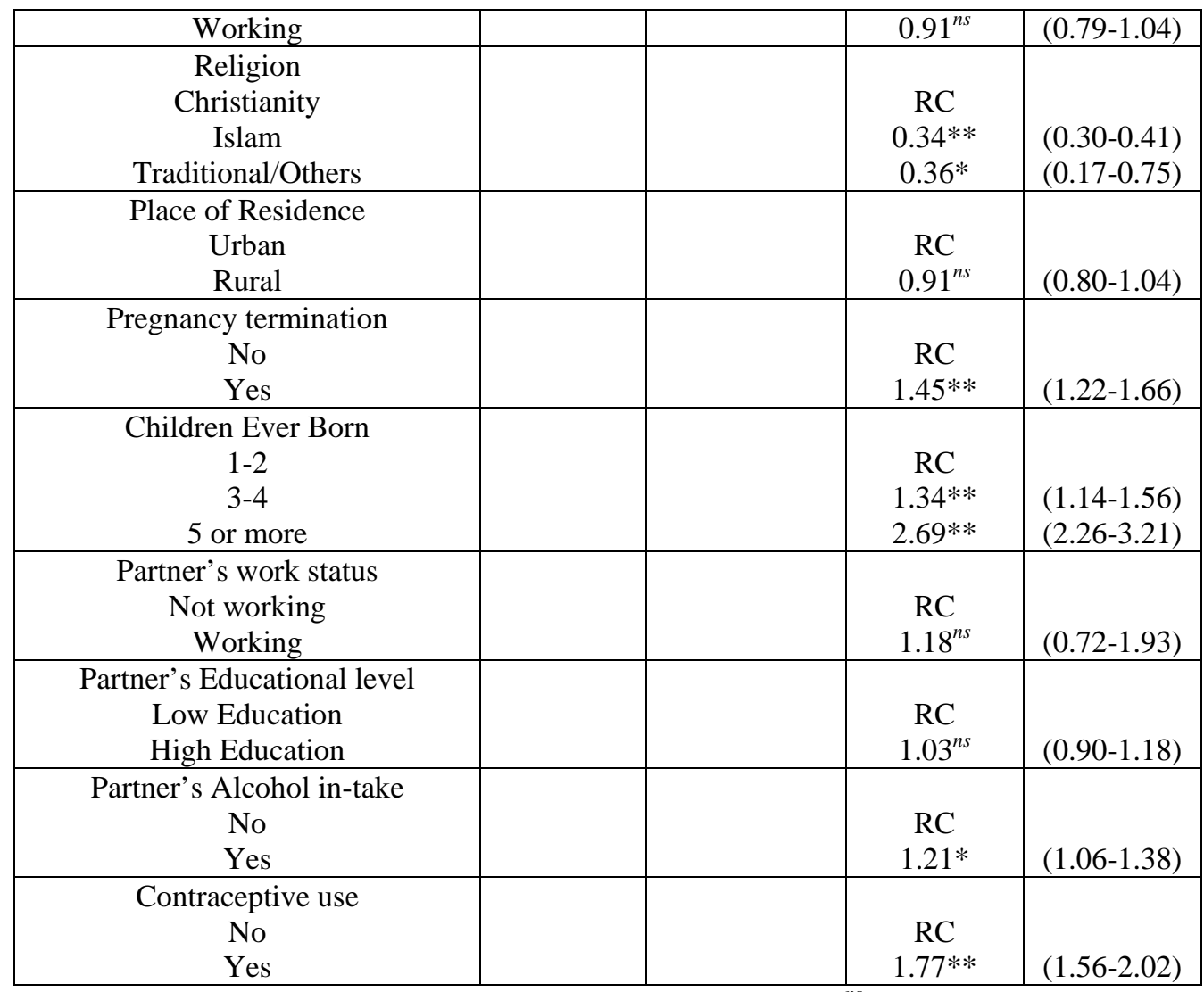

Note: RC: Reference Category; ${ }^{* *} p<0.001, p<0.01 * \&{ }^{n s}$ Not Significant

The multivariable logistical regression models predicting unintended pregnancy were shown in Table 3. First model was an unadjusted model which examined the relationship between sexual violence (main independent variable) and unintended pregnancy (outcome variable). Result indicated that respondents who had had sexual violence experience were at higher odds ratios (2.92) of experiencing unwanted pregnancy than their other counterparts who never experienced sexual violence. This, however, implied that some births significantly occurred unwanted as a result of sexual abuse or assault by partners/husbands. Further results in Model 2 after adjusting for respondents and partner/husband backgrounds disclosed that most of the variables were significantly associated with unintended pregnancy except for respondents' work status, place of residence, work status and educational level of partners. According to Table 3, respondents that had experienced sexual violence were more likely (2.73 times) to be impregnated unwillingly. The odds of unintended pregnancy reduces as age increases; Women that were 35 years or more were 57\% less likely to have unwanted pregnancy; while the chance to experience unintended pregnancy was more with high 
educated respondents than low educated respondents (1.35 times). In addition, respondents that were in middle and rich class in the wealth category were more likely to be exposed to unwanted pregnancy (1.51 and 1.29 times respectively). The odds ratio of unintended pregnancy was significantly higher Christians' women than all other religious faiths. Odds of unwanted pregnancy was significantly higher among women with cases of pregnancy termination and women whose CEB(Children Ever Born) was more than 2 children. Respondents whose husbands/partners drink alcohol and those women who used contraceptive were significantly $21 \%$ and $77 \%$ respectively more likely to have unintended pregnancy than their other counterparts.

\section{Discussions}

Despite the widespread of gender-based violence and abuse cases all over the world, covertly is still a common language in reporting cases of gender-based domestic violence most especially in developing countries of the world. Many violence against women go unreported and some that were reported were swept under the carpet without having the culprits facing the wrath of the law. Despite the fact that most communities and societies frown at violence against women, the reality is that violations against women's human rights are often sanctioned under the garb of cultural practices and norms, or through misinterpretation of religious tenets (UNICEF, 2000). And the most regretting part is that appreciable number of the domestic violence are perpetrated by women's husbands or close partners (spousal violence) (Hindin, Kishor \& Ansara, 2008; Bibi, Asfaq, Shaikh \& Qureshi, 2014), this makes investigation and proper law application impossible and difficult most times. Considering the socio-economic, demographic, health and psychological negative implications of spousal violence one would know that much is still desired to be done in bringing the menace to its knee (Titilayo \& Palamuleni, 2015). Though there have been some study on gender-based violence in the study location but one area that has not been explored is the unwanted/unintended pregnancies that could be attributed to GBDV, that is, pregnancies that were likely to be as a result of coerciveness (sexual, physical or/and emotional) act from the spouses.

Employing a nationally representative weighted sample size of 15,941 Nigerian women who had specifically selected for domestic violence module we examined the likely relationship between gender-based domestic sexual violence and incidence of unwanted pregnancies based on their selfreported information in the study location. Overall, one quarter $(24.7 \%)$ of the total respondents in study who ever experienced domestic violence from their spouses or intimate sexual partners equally reported having experienced unwanted/unintended pregnancy. This result supports the findings as 
reported in literature (Kamal, 2013; Erukar, 2004; Pallito \& O’Campo, 2004; Stephenson, Koenig \& Ahmed, 2006; Gomez, Speizer \& Beauvais, 2009). The high prevalence of unwanted pregnancy among women who experienced sexual violence when compared with the rate among those who never experienced sexual violence is a pointer that domestic sexual violence contributed substantially to high unwanted pregnancy among reproductive age in the study location. Though unwanted/unintended pregnancy cut across all age groups among the respondents but it was more prevalent among the youngest age group than the others. This perhaps might be that women possess more power and confident to reject unwilling acts from their spouses or intimate sexual partners as they grew older. Higher education seems not making much impact in lowering the occurrence of unwanted pregnancy in the study location as women of higher education exhibited greater level of unwanted pregnancy than their counterparts with lower education. That is, there exist a significant positive relationship between education status and the report of unwanted pregnancy. This finding is line with the finding of Pawan, Rupesh \& Arja (2016) and Sebastian, Khan \& Sebastian (2014) in their study of factors influencing mistimed and unwanted pregnancies among Nepali women and unintended pregnancy and abortion in India respectively where they reported that education status was a positively correlated factor with prevalence of mistimed pregnancy (Pawan, Rupesh \& Arja, 2016; Sebastian, Khan \& Sebastian, 2014). By general understand or belief, higher educational status is expected to be an avenue aiding women empowerment and thus assist in reducing domestic violence against them which could invariably reduce chances of having unwanted pregnancy. Two potential explanations for this relationship between education and unwanted pregnancy are 1 . as reported by Sebastian \& colleagues (2014) could be the over confidence that educated women do have in taking charge and control of their reproductive situation, particularly family planning issue which could fail them and 2. As reported by Pawan, Rupesh \& Arja (2016) could be that higher education women could be more factual and report the true situation of their pregnancies as unwanted than do the non- or less educated women. Moreover, the study revealed a high prevalence of unwanted/unintended pregnancy among women who are Christian than any other religion in the study location. The plausible reasons for the high occurrence of unwanted pregnancy among Christianity could be traced to the negative attitude towards family planning and contraceptive use of some of the Christian denominations especially Catholic faith. Fertility related variables such as number children ever born, contraceptive use and experience of pregnancy termination were significantly correlated with unwanted pregnancy in Nigeria. Women with higher number of children ever 
born were found to be significantly more likely to report more experience of unwanted pregnancy than their other counterparts with fewer parity. Though this finding was in contrast to the finding as reported by Pawan, Rupesh \& Arja (2016) in their study of factors influencing mistimed and unwanted pregnancies among Nepali where they discovered that women with third or higher parity were less likely to report mistimed pregnancy, one possible explanation for our finding could be due to length of time spent with spouse since we accumulate the women's experience unlike Pawan and colleagues (ibdi) that investigated and reported the last pregnancy before the survey in Nepal. There exists a significantly higher odds (1.8) of unwanted pregnancy among women who reported contraceptive use than among those who did not use contraception. This finding looks contradictory but considering the fact that male spouses could melt unduly negative and aggressive measures to their female partners for using contraceptive might cause wrong use of contraceptive by women.

As reported in some previous studies (Fischer, Stanford, Jameson \& DeWitt, 1999; Martin, Kilgallen, Tsui, Maitra, Singh \& Kupper, 1999; Zabin, Huggins, Emerson \& Cullins, 2000; Kamal, 2013) and evident in the findings of the study GBDV is significantly related to unwanted pregnancy even after controlling for all other tested independent variables like age, educational attainment, wealth index, religion, place of residence and other fertility related variables such as number of children ever born, contraceptive use and pregnancy termination experience. By the results of this study, ever experienced gender-based violence is a significant predictor of unwanted, unplanned pregnancy in Nigeria.

\section{Strengths and limitations}

The study was conducted using a population-based nationally representative large systematically three-stage sample size survey, thus a high precision and more reliable scientific judgment that could make the results comparable with studies conducted in some other locations regardless of different backgrounds. Very much unlike previous studies of unwanted pregnancy in the study location, this present study went a step further to investigate the relationship between gender-based domestic violence and unwanted pregnancy while controlling for some other socio-economic and demographic variables. Therefore, the findings could be of a great help in designing interventions plan for maternal and child health, excess fertility related problems and high population growth issues. But being a crosssectional source of data, causal inferences could not be made within the variables. Again, recall bias cannot be overruled in the report of some of the variables most especially with the cumulative experience of ever experience 
domestic violence module in the survey. These might affect the outcome of the study.

\section{Conclusion}

The study found a significant proportion of unwanted pregnancy among women who ever experienced gender-based domestic violence in Nigeria alongside other significant correlated predictors of the dependent variable. Addressing the factors identified in this study could help reduce the menace of unwanted pregnancy and tame unnecessary population growth in the country.

\section{References:}

1. Asling-Monemi, K., Naved, R. T. \& Persson, L. A. (2008). Violence against women and the risk of under-five mortality: Analysis of community-based data from rural Bangladesh. Acta Paediatrica. 97:226-232.

2. Bibi, S., Ashfaq, S., Shaikh, F. \& Qureshi, P. M. A. 2014. Prevalence, Instigating Factors and Help Seeking Behavior of Physical Domestic Violence among Married Women of Hyderabad, Sindh. Pakistan Journal of Medical Sciences. 30(1):122125.doi:http://dx.doi.org/10.12669/pjms.301.4533http://www.pjms.c om.pk/index.php/pjms/article/view/4533.

3. Erulkar, A. S. (2004). The experience of sexual coercion among young people in Kenya. International Family Planning Perspective. 30(4):182-9.

4. Fischer, R. C., Stanford, J. B., Jameson, P. \& DeWitt, M. J. (1999). Exploring the concepts of intended, planned and wanted pregnancy. Journal of Family Practice. 48:117-22.

5. Gómez, A. M., Speizer, I. S. \& Beauvais, H. (2009). Sexual violence and reproductive health among youth in Port-au-Prince, Haiti. Journal of Adolescent Health 44(5):508-10.

6. Hammoury, N., Khawaja, M., Mahfoud, Z., Afifi, R. A. \& Madi, H. (2009). Domestic violence against women during pregnancy: The case of Palestinian refugees attending an antenatal clinic in Lebanon. Journal of Women's Health. 18:337-345.

7. Heise, L., Ellsberg, M. \& Gottemoeller, M. (1999). Ending violence against women. Population Reports: Series L, No.11. Baltimore, Maryland: Population Information Program, Johns Hopkins University School of Public Health, USA.

8. Hindin, M. J., Kishor, S. \&. Ansara, D. L. (2008). Intimate Partner Violence among Couples in 10 DHS Countries: Predictors and 
Health Outcomes. Demographic Health Survey Analytical Studies No. 18. Calverton: Macro International Inc.

9. Hossain, M., Bose, M. L. \& Ahmad, A. (2004). Nature and impact of women's participation in economic activities in rural Bangladesh: Insights from household surveys. Economic Review. Directorate of Economics and Statistics Planning, (Statistics) Department Government of Tripura, Agartala.

10. Jewkes, R. (2002). Intimate partner violence: Causes and prevention. Lancet 359 (9315). 1423-1429.

11. Kamal, S. M. (2013). Domestic violence, Unwanted Pregnancy and Pregnancy Termination among Urban Women of Bangladesh. Journal of Family Reproductive Health. 7(1). 11-22.

12. Martin, S. L., Kilgallen, B., Tsui, A. O., Maitra, K., Singh, K. K. \& Kupper, L. L. (1999). Sexual behaviors and reproductive health outcomes: associations with wife abuse in India. Journal of American Medical Association. 282:1967-72.

13. National Population Commission [Nigeria] and United Nations Population Fund (2008). Domestic violence against women from the 2008 Nigeria Demographic and Health Survey. Abuja, Nigeria: National Population Commission and United Nations Population Fund. 2014.

14. National Population Commission (NPC) [Nigeria] and ICF International (2014), Nigeria Demographic and Health Survey 2013, Abuja, Nigeria, and Rockville, Maryland, USA: NPC and ICF International.

15. Okemini, E. \& Adekola, G. (2012). Violence Against Women in Ikwerre Ethnic Nationality of Nigeria: Challenges for Gender Equity and Development. Studies in Sociology of Science. 3(2); pp 6-12. DOI:10.3968/j.sss.19230120302.1445

16. Pallitto, C. C \& O'Campo, P. (2004). The relationship between intimate partner violence and

17. unintended pregnancy: Analysis of a national sample from Colombia. International Family Planning Perspective 30(4):165-73.

18. Pawan, A., Rupesh, G. \& Arja, R. A. (2016). Factors influencing mistimed and unwanted pregnancies among Nepali Women. Journal of Biosocial Science, 48(2): 249-266. Doi:1017/S0021932015000073.

19. Sebastian, M. P., Khan, M. E. \& Sebastian, D. (2014). Unintended pregnancy and abortion in India: Country Profile report. Population Council, New Delhi, India.

20. Stephenson, R., Jadhav, A. \& Hindin, M. (2013). Physical domestic violence and subsequent contraceptive adoption among women in 
rural India. Journal of Interpersonal Violence. 28(5): 1020-1039. Doi:10.1177/0886260512459379

21. Stephenson, R., Koenig, M. A. \& Ahmed, S. (2006). Domestic violence and symptoms of gynecologic morbidity among women in north India. International Family Planning Perspective 32(4):201-8.

22. Titilayo, A. \& Palamuleni, E. M. (2015). Spousal violence and unwanted fertility in Malawi. African Population Studies. Vol.29(2), Supplement, 2031-2047.

23. Titilayo, A., Anuodo, O. O. \& Palamuleni, E. M. (2016). Polygyny, domestic violence and under-five mortality in Nigeria. Forthcoming in African Health Sciences

24. United Nations Children's Fund (UNICEF), 2000. Domestic Violence against Women and Girls. United Nations Children's Fund Innocenti Research Centre, Innocenti Digest 6. Florence, Italy,United Nations Children's Fund.

25. United States Agency International Development (USAID). (2012). Strategy to prevent and respond to gender-based violence globally. United States Agency International Development. http://pdf.usaid.gov/pdf_doc/PDACT888.pdf.

26. Wathen, C. N. \& MacMillan, H. L. (2003). Interventions for violence against women: Scientific review. Journal of the American Medical Association. 289:589-600.

27. World Health Organization (WHO). (2002). World Report on Violence and Health: Summary. Geneva: World Health Organization.

28. Zabin, L. S., Huggins, G. R., Emerson, M. R. \& Cullins, V. E. (2000). Partner effects on a woman's intention to conceive: 'not with this partner' International Family Planning Perspectives. 2000; 32:39-45.

29. Zafar, S., Batool Z. \& Bano, S. (2005). Female participation in decision making process in family matters in district Faisalabad Pakistan. Journal of Agriculture and Social Sciences. 1(3). 285-287. 